\title{
Glycemic Control and Muscle Damage in 3 Athletes With Type 1 Diabetes During a Successful Performance in a Relay Ultramarathon: A Case Report
}

\author{
Taisa Belli, PhD; Denise V. de Macedo, PhD; Pedro P.M. Scariot, MSc; Gustavo G. de Araújo, PhD; \\ Ivan G.M. dos Reis, PhD; Fernanda L. Lazarim, PhD; Lázaro A.S. Nunes, PhD; René Brenzikofer, PhD; \\ Claudio A. Gobatto, PhD
}

From the Laboratory of Applied Sport Physiology (LAFAE), School of Applied Sciences, University of Campinas, Limeira, SP, Brazil (Dr Belli, Mr Scariot, Drs dos Reis and Gobatto); the Laboratory of Exercise Biochemistry (LABEX), Biochemistry Department, Biology Institute, University of Campinas, Campinas, SP, Brazil (Drs de Macedo, Lazarim, and Nunes); the Sports Science Research Group - Federal University of Alagoas (UFAL), Maceio AL, Brazil (Dr de Araújo); and the Laboratory of Instrumentation for Biomechanics (LIB), Faculty of Physical Education, University of Campinas, Campinas, SP, Brazil (Dr Brenzikofer).

\begin{abstract}
Ultramarathon races are fairly demanding and impose substantial physiological stress on healthy athletes. These competitions may thus be considerably more challenging for individuals with diabetes. This case study aims to describe glycemic control, muscle damage, inflammation, and renal function in 3 athletes with type 1 diabetes during a successful performance in a relay ultramarathon. The team completed the race in 29 hours and 28 minutes, earning third place. The total distance covered by each athlete was $68.7,84.5$, and $65.1 \mathrm{~km}$. Most blood glucose levels showed that athletes were in a zone where it was safe to exercise $(90-250 \mathrm{mg} / \mathrm{dL}$ or $5.0-13.9 \mathrm{mmol} / \mathrm{L})$. Creatine kinase, lactate dehydrogenase, and aspartate aminotransferase serum levels increased 1.2- to 50.7-fold prerace to postrace, and were higher than the reference ranges for all the athletes postrace. Blood leukocytes, neutrophils, and serum C-reactive protein (CRP) increased 1.6- to 52-fold prerace to postrace and were higher than the reference ranges for 2 athletes after the race. Serum creatinine increased 1.2-fold prerace to postrace for all the athletes but did not meet the risk criteria for acute kidney injury. In conclusion, our main findings show evidence of satisfactory glycemic control in athletes with type 1 diabetes during a relay ultramarathon. Moreover, elevation of muscle damage and inflammatory biomarkers occurred without affecting renal function and challenging the maintenance of blood glucose among athletes. These findings are novel and provide an initial understanding of the physiological responses in athletes with type 1 diabetes during ultramarathon races.
\end{abstract}

Keywords: diabetes, ultramarathon, glycemic management, muscle damage, inflammation

\section{Introduction}

Ultramarathons are foot race competitions that vary from 50 to $1600 \mathrm{~km}$ and are performed on various terrains. Tolerating the physiological impact is fairly demanding for ultrarunners, ${ }^{1-5}$ and could be more challenging for chronic disease patients. Athletes with diabetes have

Corresponding author: Claudio Alexandre Gobatto, $\mathrm{PhD}$, School of Applied Sciences, University of Campinas, Pedro Zaccaria Street, 1.300, Jardim Santa Luiza, Limeira, Sao Paulo, Brazil 13484-350; e-mail: claudio.gobatto@fca.unicamp.br.

Submitted for publication October 2016.

Accepted for publication April 2017. participated in ultramarathons. ${ }^{6,7}$ However, to our knowledge, glycemic control and muscle damage resulting from these foot races were not assessed among these athletes. Here we address these issues and focus on athletes with type 1 diabetes mellitus (T1DM).

According to the American Diabetes Association, persons with T1DM who do not have complications and have good glycemic control can perform all types of exercise. ${ }^{8,9}$ During exercise, however, hypoglycemia is the most frequent and dangerous consequence for T1DM patients. ${ }^{10}$ This may be due to the inability of the pancreas to promote a reduction in plasma insulin levels during exercise, combined with an exercise-induced glucose uptake via an 
insulin-independent mechanism. ${ }^{11}$ T1DM patients experience hypoglycemia during exercise because of increased insulin sensitivity and augmented exogenous insulin absorption rates. ${ }^{12,13}$ Some people with diabetes may present a blunted counterregulatory hormone response to exercise and an impairment in hepatic glucose production. Conversely, high-intensity exercise may lead to hyperglycemia, given an increase in plasma catecholamine concentrations and subsequent liver glycogenolysis elevation. ${ }^{10-14}$ Therefore, glycemic control constitutes a challenge for T1DM patients during exercise, and glycemic management strategies are essential. ${ }^{12}$

Ultramarathons cause marked muscle damage in healthy individuals $^{2,3,15,16}$ because of mechanical, metabolic, and inflammatory processes. ${ }^{17}$ Muscle protein blood level and muscle soreness are common measures of muscle damage. ${ }^{18,19}$ Generally, muscle damage is unrelated to health complications. However, the release of excessive amounts of intramuscular proteins into the blood stream can lead to precipitation in kidney tubules, negatively affecting the renal function. ${ }^{18}$ This can become clinically relevant to ultrarunners with T1DM who have an increased risk of kidney complications related to the pathophysiology of diabetes. ${ }^{20}$ Exercise-induced muscle damage can lead to transient insulin resistance in healthy subjects. ${ }^{21}$ Muscle damage initiates a series of immune reactions, which involves the production of cytokines and leukocyte infiltration into the damaged muscle, systemic release of leukocytes and cytokines, ${ }^{22}$ and the production of a large number of acute-phase proteins. ${ }^{23}$ Transient insulin resistance is caused by inflammatory factors generated by muscle damage. ${ }^{24}$ Therefore, profound muscle damage and inflammatory responses observed in ultramarathons ${ }^{1,2,16}$ may influence glycemic control in athletes with T1DM.
Based on the above statements, this study aims to describe glycemic control and muscle damage in a team comprising 3 athletes with T1DM during their participation in a relay ultramarathon. We also describe the athletes' inflammatory response and renal function during the competition.

\section{Methods}

\section{SUBJECTS}

Three male athletes were studied during their participation in the Brazil 135 Ultramarathon relay race. Demographics of the athletes are presented in Table 1. They all had satisfactory glycemic control over the preceding year, as glycated hemoglobin (HbA1c) values ranged from 6.9 to $8.7 \%(52-72 \mathrm{mmol} / \mathrm{mol})$. They received multiple daily injections via insulin pen (Athlete A: intermediate and short-acting human insulin and Athlete B: long and rapid-acting analog insulin) or continuous subcutaneous infusion via insulin pump (Athlete C: rapid-acting analog insulin). This study was approved by the Ethics Research Committee of the São Paulo State University (UNESP) (no. 037/2008), and informed written consent was given by each athlete.

\section{RESEARCH DESIGN AND RACE DETAILS}

This descriptive field study occurred at the Brazil 135 Ultramarathon. This $217-\mathrm{km}$ international foot race is a single-stage mountain ultramarathon performed on dirt roads in the most difficult segment of a Brazilian pilgrimage route called "The Walk of Faith" (Mantiqueira Mountains, Brazil), with a total positive and negative elevation change of 12,200 m (Figure 1).

Table 1. Characteristics of athletes with Type 1 diabetes mellitus

\begin{tabular}{|c|c|c|c|}
\hline & Athlete A & Athlete B & Athlete $C$ \\
\hline Age (years) & 34 & 35 & 37 \\
\hline Height $(\mathrm{cm})$ & 179 & 166 & 173 \\
\hline Body weight (kg) & 77.2 & 67.8 & 67.8 \\
\hline Body mass index $\left(\mathrm{kg} / \mathrm{m}^{2}\right)$ & 24.1 & 24.6 & 22.7 \\
\hline Body fat $(\%)$ & 12.3 & 13.3 & 9.5 \\
\hline Diabetes mellitus diagnosis (years) & 30 & 14 & 23 \\
\hline \multicolumn{4}{|l|}{ Usual insulin dose } \\
\hline Basal (IU/day) & 38 & 22 & 22.8 \\
\hline Bolus (IU/10 g CHO) & 0.8 & 0.9 & 0.8 \\
\hline Running history (years) & 16 & 13 & 14 \\
\hline Marathon history (n) & 2 & 38 & 20 \\
\hline Best marathon time (hours:minutes) & $4: 30$ & $3: 38$ & 4:06 \\
\hline Training distance (km/week) & $40-100$ & $40-140$ & $50-100$ \\
\hline Critical velocity intensity ( $\mathrm{km} / \mathrm{hour})$ & 13.8 & 13.4 & 14.0 \\
\hline
\end{tabular}

CHO, carbohydrate ingestion. 


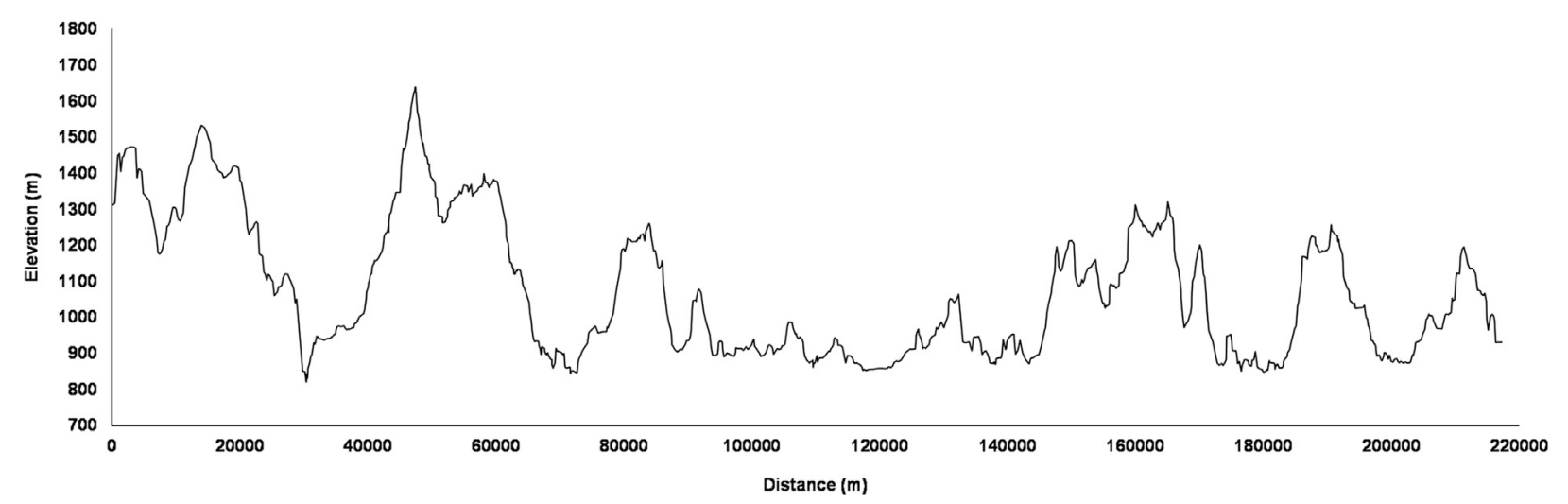

Figure 1. Elevation profile throughout the Brazil 135 Ultramarathon route.

Runners may participate in the individual (solo) or relay race (teams comprising 2, 3, or 4 athletes) and must arrive at the finish line within 60 hours to be considered an official finisher. Seven teams comprising 3 athletes, including the team comprising our athletes, participated in the race in 2009. Six of these teams completed the competition, and their race time ranged from 21 hours and 35 minutes to 43 hours and 30 minutes. Volunteers could eat and drink ad libitum during the race. Ambient temperatures were 8 to $30^{\circ} \mathrm{C}$.

\section{AEROBIC PERFORMANCE TEST}

Critical velocity was individually determined 1 week before the competition from 4 maximal runs of 800 , 1200,1600 , and $2000 \mathrm{~m}$ performed randomly once daily. Critical velocity was determined by the angular coefficient of the linear fit of distance versus running time. ${ }^{25}$ Critical velocity intensity was found to occur at approximately midway between anaerobic threshold and maximal oxygen uptake. $^{26}$ Critical velocity denoted the highest sustainable rate of the athletes' aerobic metabolism.

\section{RACE MEASUREMENTS AND BLOOD ANALYSES}

Records of distance covered and duration of exercise bouts (Garmin Forerunner 305), blood glucose, and insulin requirements (Accu-Chek glucose meter, Roche Diagnostics) were obtained from our athletes during the relay race. The athletes conducted glycemic measurements for both prebouts and postbouts of exercise during the relay race. They conducted additional blood glucose analyses during longer bouts of exercise. Race time was obtained from official race reports.

The athletes were also evaluated prerace and postrace. Prerace measurements were performed in the afternoon before the race at 5 hours postprandial, whereas postrace evaluation occurred immediately after the race. Athletes completed a questionnaire on basic demographics and prerace training and underwent anthropometric evaluations. Twelve $\mathrm{mL}$ blood samples were collected from each athlete by a certified nurse and distributed across a number of tests. Automated equipment (Autolab 18, Boehringer Mannheim and KX-21N Sysmex) and typical laboratory procedures were used to generate the following blood constituents: creatine kinase (CK), lactate dehydrogenase (LDH), aspartate aminotransferase (AST), creatinine, urea, total protein, albumin, urate (Wiener kits), C-reactive protein (CRP) (Biotécnica kit), total and differential white cells counts, red blood cells, and platelets parameters. ${ }^{27}$ All blood serum analysis results were corrected for changes in plasma volume estimated using total protein. ${ }^{28}$

Athletes rated their level of muscle soreness prerace and postrace. Runners selected a number that best described any general feeling of pain, soreness, and muscles ache using a 10-point Likert scale: 1 (no soreness), 2.5 (dull, vague ache), 4 (slight soreness), 5.5 (more than slight soreness), 7 (sore), 8.5 (very sore), and 10 (unbearably sore). ${ }^{2}$

\section{Results}

The team completed the race in 29 hours and 28 minutes, earning third place. The athletes completed the competition in 21 bouts of exercise: 7 bouts alternately performed by each athlete. The total distance covered by Athletes A, B, and C was $68.7,84.5$, and $65.1 \mathrm{~km}$, respectively.

Most glycemic values ranged from 90 to $250 \mathrm{mg} / \mathrm{dL}$ (5.0-13.9 $\mathrm{mmol} / \mathrm{L}$ ) during the race (Figure 2), which is a safe range for diabetic individuals who want to exercise. ${ }^{8}$ Athletes took their usual insulin dose a day before the race. Insulin dosage adjustments throughout the competition were individually conducted and were fundamentally based on the interaction among glycemic levels, carbohydrate counts, and exercise bout 


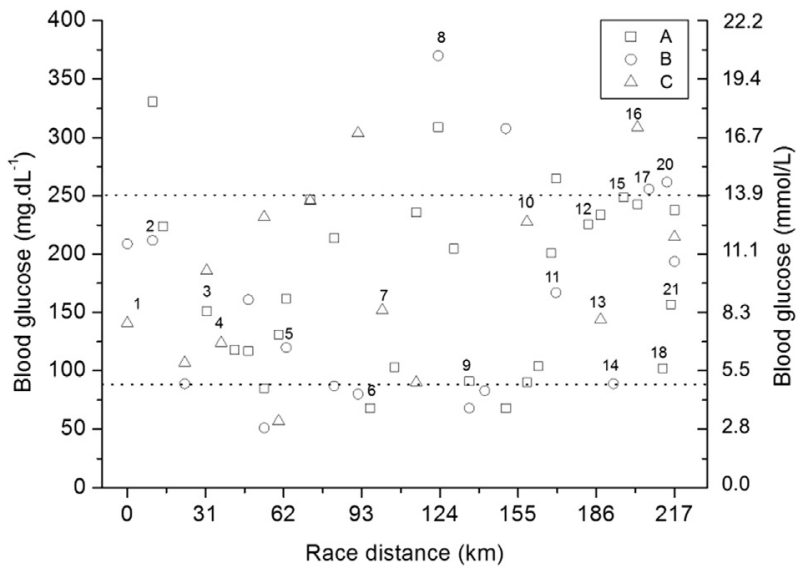

Figure 2. Blood glucose responses of 3 athletes (A, B, and C) during the race. Dot lines delimit the range from 90 to $250 \mathrm{mg} / \mathrm{dL}(5.0-13.9$ $\mathrm{mmol} / \mathrm{L}$ ) of blood glucose. Numerical order above the markers (squares, circles, and triangles) represents which athlete (A, B, and C) was running during the competition. Segment 19 was run by athlete $C$. This is omitted from the figure because there was no blood glucose measurement.

characteristics. Athlete A took $75 \%$ of the basal dose plus $50 \%$ of the bolus insulin dose, Athlete B took $85 \%$ of the basal dose plus $10 \%$ of the bolus insulin dose, and Athlete $\mathrm{C}$ took $50 \%$ of the basal dose plus $50 \%$ of the bolus insulin dose.

Muscle protein serum levels were higher than the reference ranges for all athletes postrace (Table 2), with marked percentage changes (prerace to postrace) of serum CK $(\mathrm{A}=844 \%, \mathrm{~B}=4978 \%$, and $\mathrm{C}=891 \%)$, $\mathrm{LDH}(\mathrm{A}=123 \%, \mathrm{~B}=161 \%$, and $\mathrm{C}=82 \%)$, and $\mathrm{AST}$ $(\mathrm{A}=23 \%, \mathrm{~B}=934 \%$, and $\mathrm{C}=106 \%)$. Moreover, muscle soreness increased from 1 (no soreness) to 2.5 (dull, vague ache) for Athlete A and from 1 (no soreness) to 5.5 (more than slight soreness) for Athletes B and C prerace to postrace. Considering all the data, we observed that athletes had high muscle damage after the competition.

Blood leukocytes, neutrophils, and serum CRP were higher than the reference ranges for Athletes A and B after the race. Blood monocytes were higher than the reference ranges for all athletes after the race (Table 2). Increases in white blood cells count and acute-phase protein (ie, CRP) indicated that the athletes showed an inflammatory response prerace to postrace.

Urea levels were higher than the reference ranges for all athletes after the race. However, serum creatinine increased 1.2-fold prerace to postrace in all athletes (Table 2) and did not meet the risk criteria for acute kidney injury (ie, increased serum creatinine x 1.5)..$^{29}$ Finally, slight changes were observed for total protein, albumin, urate, erythrocytes, and platelets prerace versus postrace (Table 2).

\section{Discussion}

We aimed to describe glycemic control, muscle damage, inflammation, and renal function in a team comprising 3 athletes with T1DM during their participation in a 217$\mathrm{km}$ relay ultramarathon. Previous studies reported these responses based on $226^{-30}$ and $452-\mathrm{km}^{31}$ triathlon competitions in these athletes. Recent investigations documented that they were able to complete $161-\mathrm{km}$ solo ultramarathon races. ${ }^{6,7}$ However, to our knowledge, no study investigated these physiological responses as a result of an ultramarathon among these athletes. Our main findings indicate that they could maintain good glycemic control through appropriate management strategies during the race. Moreover, elevation of muscle damage and inflammatory biomarkers occurred without affecting the athletes' renal function and glycemic control.

The results presented herein expand the limited number of findings about glycemic control in the study athletes during endurance ${ }^{32,33}$ and ultraendurance ${ }^{30,31}$ competitions. Additionally, $73 \%$ of the blood glucose analyses showed that these athletes were in a zone where it was safe to exercise $(90-250 \mathrm{mg} / \mathrm{dL}$ or $5.0-13.9$ $\mathrm{mmol} / \mathrm{L}){ }^{8}$ Among the 60 blood glucose measurements performed by the team, only 3 hypoglycemia records $(<70 \mathrm{mg} / \mathrm{dL} \text { or } 3.9 \mathrm{mmol} / \mathrm{L})^{20}$ were seen in the athletes during the race.

Insulin dose adjustment conducted on an individual basis was essential for the athletes to maintain a satisfactory glycemic level during the race. Athletes had a solid expertise about insulin pharmacokinetics, glycemic monitoring and interpretation, balanced diet, and exercise physiology. Consistent with these findings, Toni et al. ${ }^{13}$ and Lumb and Gallen ${ }^{14}$ reported that the exact adjustments of insulin dose during exercise must be made from each athlete's own experience.

Our results showed that the athletes in this study, running $\sim 65$ to $85 \mathrm{~km}$ over episodic periods, had similar increases in muscle damage and inflammatory biomarkers, as reported previously where 1 athlete was evaluated after a $452-\mathrm{km}$ triathlon competition. ${ }^{31}$ Different from triathlon competitions, mountain ultramarathons are performed on off-road trails, coastal mountains, and paths with considerable cumulative downhill courses, ${ }^{5,34}$ resulting in substantial muscle damage and subsequent inflammatory responses. ${ }^{22}$

High serum CK values are common after ultramarathons, but rarely result in adverse consequences among healthy ultrarunners. ${ }^{15}$ Athlete B presented the highest serum CK levels (6930 U/L) among our athletes, which may be attributed to him running a longer distance $(84 \mathrm{~km})$ at a higher average exercise intensity ( $\sim 62 \%$ of critical velocity) than Athletes A $(68.7 \mathrm{~km}, 57 \%$ of critical velocity) and C (65.1 $\mathrm{km}$ and $61 \%$ critical velocity). Exercise duration and 
Table 2. Biochemical and hematological measures of the athletes prerace and postrace

\begin{tabular}{|c|c|c|c|c|c|c|c|}
\hline & \multirow{2}{*}{$\frac{\text { Normal }}{\text { Range }}$} & \multicolumn{2}{|c|}{ Athlete A } & \multicolumn{2}{|c|}{ Athlete B } & \multicolumn{2}{|c|}{ Athlete $C$} \\
\hline & & Prerace & Postrace & Prerace & Postrace & Prerace & Postrace \\
\hline CK (U/L) & 24-195 & 74 & 699 & 136 & 6907 & 268 & 2658 \\
\hline AST (U/L) & $\leq 38$ & 82.9 & 102 & 16.7 & 173 & 27 & 106 \\
\hline LDH (U/L) & $230-460$ & 470 & 1053 & 327 & 855 & 501 & 914 \\
\hline $\mathrm{CRP}(\mathrm{mg} / \mathrm{L})$ & $<6$ & 1.0 & 10.1 & 1.3 & 12.7 & 0.1 & 5.2 \\
\hline Urea $(\mathrm{mmol} / \mathrm{l})$ & $2.5-6.6$ & 6.8 & 10.8 & 6.5 & 15.9 & 7.1 & 9.8 \\
\hline Creatinine $(\mu \mathrm{mol} / \mathrm{l})$ & $60-120$ & 88.4 & 103.8 & 103.4 & 126.6 & 116.7 & 139.4 \\
\hline Total protein $(\mathrm{g} / \mathrm{L})$ & $61-79$ & 64 & 65 & 65 & 76 & 71 & 69 \\
\hline Albumin $(\mathrm{g} / \mathrm{L})$ & $35-48$ & 37 & 41 & 38 & 45 & 49 & 51 \\
\hline Urate $(\mu \mathrm{mol} / \mathrm{l})$ & $150-360$ & 244 & 294 & 250 & 326 & 214 & 303 \\
\hline Leukocytes $\left(\times 10^{9} / \mathrm{L}\right)$ & $4.00-11.00$ & 9.62 & 15.52 & 6.98 & 11.97 & 5.87 & 9.31 \\
\hline Neutrophils $\left(\times 10^{9} / \mathrm{L}\right)$ & $2.00-7.59$ & 3.35 & 8.16 & 4.63 & 7.97 & 3.51 & 5.68 \\
\hline Lymphocytes $\left(\times 10^{9} / \mathrm{L}\right)$ & $1.50-4.00$ & 5.05 & 5.80 & 1.74 & 2.76 & 1.63 & 2.40 \\
\hline Monocytes $\left(\times 10^{9} / \mathrm{L}\right)$ & $0.2-0.8$ & 1.19 & 1.44 & 0.51 & 1.19 & 0.48 & 1.14 \\
\hline Eosinophils $\left(\times 10^{9} / \mathrm{L}\right)$ & $0.1-0.4$ & 0.09 & 0.06 & 0.09 & 0.01 & 0.23 & 0.05 \\
\hline Basophils $\left(\times 10^{9} / \mathrm{L}\right)$ & $<0.1$ & 0.04 & 0.05 & 0.01 & 0.02 & 0.02 & 0.04 \\
\hline Erythrocyte $\left(\times 10^{12} / \mathrm{L}\right)$ & $4.70-6.00$ & 5.32 & 5.17 & 5.05 & 5.36 & 5.95 & 6.27 \\
\hline Hematocrit $(\%)$ & $42-52$ & 44.9 & 45.1 & 43.3 & 47.2 & 48.5 & 51.9 \\
\hline Hemoglobin $(\mathrm{g} / \mathrm{L})$ & $135-180$ & 153 & 151 & 149 & 159 & 170 & 179 \\
\hline MCV (fL) & $78-100$ & 84.4 & 87.2 & 85.7 & 88.1 & 81.5 & 82.8 \\
\hline $\mathrm{MCH}(\mathrm{pg})$ & $27-31$ & 28.8 & 29.2 & 29.5 & 29.7 & 28.6 & 28.5 \\
\hline $\mathrm{MCHC}(\mathrm{g} / \mathrm{L})$ & $31-36$ & 34.1 & 33.5 & 34.4 & 33.7 & 35.1 & 34.5 \\
\hline RDW (\%) & $10-15$ & 13.1 & 13.9 & 13.3 & 14.7 & 12.8 & 13.6 \\
\hline Platelets $\left(\times 10^{9} / \mathrm{L}\right)$ & $150-450$ & 265 & 325 & 265 & 341 & 191 & 206 \\
\hline
\end{tabular}

$\mathrm{MCV}$, mean corpuscular volume; $\mathrm{MCH}$, mean corpuscular hemoglobin; $\mathrm{MCHC}$, mean corpuscular hemoglobin concentration; RDW, red cell distribution width.

intensity are reportedly associated with higher muscle damage. ${ }^{18}$ Athlete B showed the highest postrace blood urea level $(15.98 \mathrm{mmol} / \mathrm{L})$. However, leakage of muscle cell contents into the circulation was insufficient to elicit renal function impairments. We observed that increases in serum creatinine prerace to postrace did not meet the risk criteria for acute kidney injury ${ }^{29}$ for all athletes.

Increases in muscle damage biomarkers observed herein did not challenge blood glucose maintenance among the study athletes. Although exercise commonly improves insulin sensitivity, it may paradoxically promote transient insulin resistance if it causes muscle damage. ${ }^{21}$ The mechanism underlying exercise-induced insulin resistance may be associated with the acute-phase response, impairment in the insulin signaling pathway, ${ }^{24}$ and decreased noninsulin-mediated glucose uptake $^{35}$ This effect is observed in people unaccustomed to exercise and attenuated with repeated exposures. Multiple bouts of eccentric exercise-induced muscle damage have failed to elicit disruptions in glucose homeostasis in healthy subjects. ${ }^{36-38}$ Extending this prior knowledge, we found evidence that repeated bouts of exercise increased muscle damage biomarkers and did not appear to influence the glycemic control among our athletes.

\section{Conclusions}

We observed satisfactory glycemic control in 3 athletes with T1DM who successfully completed a relay ultramarathon. Elevation of muscle damage and inflammatory biomarkers occurred without affecting renal functions and challenging blood glucose maintenance among athletes. These findings are novel and provide an initial understanding of the physiological responses in the study athletes during ultramarathon races. Future investigations in a large sample, even during an individual (solo) ultramarathon, can better demonstrate these case report findings. Late hypoglycemia, ${ }^{10-14,32}$ pronounced muscle damage, and inflammatory conditions ${ }^{1,16}$ may occur hours after the exercise has finished, which could constitute a possible limitation of the present investigation. Future studies on the participation of these athletes in ultramarathon events should also focus on these issues.

Acknowledgments: The authors would like to thank the volunteers, organizers, and staff of the Brazil 135 Ultramarathon.

Author Contributions: Study design (TB) (CAG); conducted analyses (TB) (CAG); wrote the manuscript (TB) (CAG); assisted in acquisition, analysis, and interpretation of data (PPMS) (GGA) (IGMR) (FLL) (LASN); reviewed and edited the article (PPMS) (GGA) (IGMR) (FLL) (LASN); substantial contribution including conception and design of the study (DVM) (RB); critical revision of the manuscript 
(DVM) (RB); approval of final manuscript (TB) (DVM) (PPMS) (GGA) (IGMR) (FLL) (LASN) (RB) (CAG).

Financial/Material Support: Fundação de Amparo à Pesquisa do Estado de São Paulo (FAPESP) (Proc. 2009/08535-5), Coordenação de Aperfeiçoamento de Pessoal de Nível Superior (CAPES) and Conselho Nacional de Desenvolvimento Científico e Tecnológico (CNPq) (Proc. 305650/2009-2).

Disclosures: None.

\section{References}

1. Margeli A, Skenderi K, Tsironi M, et al. Dramatic elevations of interleukin-6 and acute-phase reactants in athletes participating in the ultradistance foot race spartathlon: severe systemic inflammation and lipid and lipoprotein changes in protracted exercise. J Clin Endocrinol Metab. 2005;90:3914-3918.

2. Nieman DC, Dumke CL, Henson DA, McAnulty SR, Gross SJ, Lind RH. Muscle damage is linked to cytokine changes following a $160-\mathrm{km}$ race. Brain Behav Immun. 2005;19:398-403.

3. Skenderi KP, Kavouras SA, Anastasiou CA, Yiannakouris N, Matalas AL. Exertional rhabdomyolysis during a 246$\mathrm{km}$ continuous running race. Med Sci Sports Exerc. 2006;38:1054-1057.

4. Khodaee M, Torres DR. Corneal opacity in a participant of a 161-km mountain bike race at high altitude. Wilderness Environ Med. 2016;27:274-276.

5. Kupchak BR, Kraemer WJ, Hoffman MD, Phinney SD, Volek JS. The impact of an ultramarathon on hormonal and biochemical parameters in men. Wilderness Environ Med. 2014;25:278-288.

6. Hoffman MD, Krishnan E. Health and exercise-related medical issues among 1,212 ultramarathon runners: baseline findings from the Ultrarunners Longitudinal TRAcking (ULTRA) Study. PLoS One. 2014;9:e83867.

7. Khodaee M, Riederer M, VanBaak K, Hill JC. Ultraendurance athletes with type 1 diabetes: Leadville 100 experience. Wilderness Environ Med. 2015;26:273-275.

8. Colberg SR, Sigal RJ, Yardley JE, et al. Physical activity/ exercise and diabetes: a position statement of the American Diabetes Association. Diabetes Care. 2016;39:2065-2079.

9. Zinman B, Ruderman N, Campaigne BN, Devlin JT, Schneider SH, American Diabetes Association, Physical activity/exercise and diabetes mellitus. Diabetes Care. 2003;26(suppl 1):S73-S77.

10. Jimenez CC, Corcoran MH, Crawley JT, et al. National athletic trainers' association position statement: management of the athlete with type 1 diabetes mellitus. J Athl Train. 2007;42:536-545.

11. Riddell MC, Perkins BA. Type 1 diabetes and vigorous exercise: applications of exercise physiology to patient management. Can J Diab. 2006;30:63-71.

12. Gallen IW, Hume C, Lumb A. Fuelling the athlete with type 1 diabetes. Diabetes Obes Metab. 2011;13:130-136.

13. Toni S, Reali MF, Barni F, Lenzi L, Festini F. Managing insulin therapy during exercise in type 1 diabetes mellitus. Acta Biomed. 2006;77(suppl 1):34-40.
14. Lumb AN, Gallen IW. Diabetes management for intense exercise. Curr Opin Endocrinol Diabetes Obes. 2009;16: 150-155.

15. Hoffman MD, Ingwerson JL, Rogers IR, Hew-Butler T, Stuempfle KJ. Increasing creatine kinase concentrations at the 161-km Western States Endurance Run. Wilderness Environ Med. 2012;23:56-60.

16. Wu HJ, Chen KT, Shee BW, Chang HC, Huang YJ, Yang RS. Effects of $24 \mathrm{~h}$ ultra-marathon on biochemical and hematological parameters. World J Gastroenterol. 2004;10: 2711-2714.

17. Clarkson PM, Sayers SP. Etiology of exercise-induced muscle damage. Can J Appl Physiol. 1999;24:234-248.

18. Banfi G, Colombini A, Lombardi G, Lubkowska A. Metabolic markers in sports medicine. Adv Clin Chem. 2012;56:1-54.

19. Cheung K, Hume P, Maxwell L. Delayed onset muscle soreness: treatment strategies and performance factors. Sports Med. 2003;33:145-164.

20. American Diabetes Association, Standards of medical care in diabetes-2016. Diabetes Care. 2016;39(suppl 1): S1-S112.

21. Tee JC, Bosch AN, Lambert MI. Metabolic consequences of exercise-induced muscle damage. Sports Med. 2007;37: $827-836$.

22. Peake J, Nosaka K, Suzuki K. Characterization of inflammatory responses to eccentric exercise in humans. Exerc Immunol Rev. 2005;11:64-85.

23. Pedersen BK, Hoffman-Goetz L. Exercise and the immune system: regulation, integration, and adaptation. Physiol Rev. 2000;80:1055-1081.

24. Del Aguila LF, Krishnan RK, Ulbrecht JS, et al. Muscle damage impairs insulin stimulation of IRS-1, PI 3-kinase, and Akt-kinase in human skeletal muscle. Am J Physiol Endocrinol Metab. 2000;279:E206-E212.

25. Kranenburg KJ, Smith DJ. Comparison of critical speed determined from track running and treadmill tests in elite runners. Med Sci Sports Exerc. 1996;28:614-618.

26. Jones AM, Vanhatalo A, Burnley M, Morton RH, Poole DC. Critical power: implications for determination of VO2max and exercise tolerance. Med Sci Sports Exerc. 2010;42:1876-1890.

27. Dalanhol M, Barros M, Mazuchelli J, Silva PH, Hashimoto Y, Largura A. Storage effects on peripheral blood samples as identified from automated hemograms [in Spanish]. Rev Bras Hematol Hemoter. 2010;32:16-22.

28. Ohira Y, Ito A, Ikawa S. Correction of water content and solute concentration in blood during hemoconcentration. J Appl Physiol Respir Environ Exerc Physiol. 1977;42: 739-743.

29. Bellomo R, Ronco C, Kellum JA, Mehta RL, Palevsky P, ADQI workgroup, Acute renal failure - definition, outcome measures, animal models, fluid therapy and information technology needs: the Second International Consensus Conference of the Acute Dialysis Quality Initiative (ADQI) Group. Crit Care. 2004;8:R204-R212.

30. Boehncke S, Poettgen K, Maser-Gluth C, Reusch J, Boehncke WH, Badenhoop K. Endurance capabilities of 
triathlon competitors with type 1 diabetes mellitus [in German]. Dtsch Med Wochenschr. 2009;134:677-682.

31. Vlahek P, Car S, Ostroski I. Sweet $452 \mathrm{~km}$-a report on the first type 1 diabetes patient to finish Double Ironman, a 30-hour endurance triathlon race. Croat Med J. 2013;54:306-307.

32. Cauza E, Hanusch-Enserer U, Strasser B, et al. Continuous glucose monitoring in diabetic long distance runners. Int J Sports Med. 2005;26:774-780.

33. Murillo S, Brugnara L, Novials A. One year follow-up in a group of half-marathon runners with type-1 diabetes treated with insulin analogues. J Sports Med Phys Fitness. 2010;50:506-510.

34. Zanchi D, Viallon M, Le Goff C, et al. Extreme mountain ultra-marathon leads to acute but transient increase in cerebral water diffusivity and plasma biomarkers levels changes. Front Physiol. 2016;7:664.
35. Ide K, Higaki Y, Nishizumi M, Kiyonaga A, Shindo M, Tanaka H. Impaired non-insulin mediated glucose uptake after downhill running in rats. Life Sci. 1996;59: 1601-1605.

36. Gonzalez JT, Barwood MJ, Goodall S, Thomas K, Howatson G. Alterations in whole-body insulin sensitivity resulting from repeated eccentric exercise of a single muscle group: a pilot investigation. Int J Sport Nutr Exerc Metab. 2015;25:405-410.

37. Green MS, Doyle JA, Ingalls CP, Benardot D, Rupp JC, Corona BT. Adaptation of insulin-resistance indicators to a repeated bout of eccentric exercise in human skeletal muscle. Int J Sport Nutr Exerc Metab. 2010;20:181-190.

38. Paschalis V, Nikolaidis MG, Theodorou AA, et al. A weekly bout of eccentric exercise is sufficient to induce healthpromoting effects. Med Sci Sports Exerc. 2011;43:64-73. 